\title{
PROFESSIONAL DEVELOPMENT: THE CHALLENGES OF ACTION RESEARCH IMPLEMENTATION IN KAZAKHSTAN
}

\author{
MSc in Educational Leadership Gulzina Nagibova \\ Kazakhstan, Uralsk, Nazarbayev Intellectual School of Physics and Mathematics in Uralsk
}

DOI: https://doi.org/10.31435/rsglobal_wos/30092019/6691

\section{ARTICLE INFO}

Received: 19 July 2019

Accepted: 16 September 2019

Published: 30 September 2019

\section{KEYWORDS}

action research, professional development, research implementation, action research challenges.

\begin{abstract}
This study explores the challenges teachers of Kazakhstani secondary schools face when conducting action research as a part of their professional development. The study also aims to provide recommendations to overcome identified action research implementation challenges. The qualitative study design is used to research and interpret the teacher's action research implementation challenges within one of the Nazarbayev Intellectual Schools in Kazakhstan.

Findings of the study demonstrated several issues teachers face while conducting action research. Firstly, teachers indicate they lack action research knowledge; secondly, they lack the necessary skills to conduct research; and finally, they do not have enough support and resources. Along with these challenges, experienced teachers provided solutions for these problems. If most of them needed continuous support from experienced colleagues, the rest believed that they have to be self-organized.
\end{abstract}

Citation: Gulzina Nagibova. (2019) Professional Development: the Challenges of Action Research Implementation in Kazakhstan. International Academy Journal Web of Scholar. 9(39), Vol.2. doi: 10.31435/rsglobal_wos/30092019/6691

Copyright: (C) 2019 Gulzina Nagibova. This is an open-access article distributed under the terms of the Creative Commons Attribution License (CC BY). The use, distribution or reproduction in other forums is permitted, provided the original author(s) or licensor are credited and that the original publication in this journal is cited, in accordance with accepted academic practice. No use, distribution or reproduction is permitted which does not comply with these terms.

Introduction. Background Information. As Fletcher \& Zuber-Skerritt (2007) stated, "Professional development is a significant issue in all workplaces for dealing most effectively with the complexity of modern society" (p. 73). This statement is also true for education. Current educational changes require from teachers continuous enhancement of their professional skills and knowledge. But effectiveness of any kind of professional development is guaranteed when the areas for improvement are determined through teachers' self- observation and consideration of their own practice. Joyce, Calhoun, and Hopkins (as cited in McGee, 2008) concluded that "if teachers research their own practice, collect, analyze and use the evidence, then this promotes improved and sustainable professional development" (p. 235). This pedagogical strategy is appropriate for action research. McNiff (2013) stated that "action research is a name given to a particular way of looking at your practice to check whether it is as you feel it should be" (p. 23).

The term "action research" was first introduced by Kurt Lewin (1946) as a tool to study effectiveness of the techniques (action) implemented to improve social relations. He defined the process of action research as a cycle that consists of several steps: planning, action, reconnaissance and evaluation (p. 38). But now action research has been developed and implemented in various spheres of social life. For example, Hardy and Rodman (2016) discussed the importance of action research in the military and came to the conclusion:

"Solutions such as action research, which address the underlying issues that perpetuate ongoing challenges in the field, can help soldiers develop the cognitive mechanisms needed to not only cope but also to thrive within complex and ambiguous operating environments". (p. 95).

Initially, Stenhouse (as cited in McNiff, 2013) developed the concept of "teachers as researchers" and stated that "teachers should be best judges of their practice" (p. 58). Thus, to make improvements in 
teaching, learning and schooling teachers and other educators widely use action research as an effective strategy. Various studies have been conducted on action research implementation in education in the context of different countries (Jaipal \& Figg, 2011; Keegan, 2016; McGee, 2008; Smith \& Sela, 2005). These literatures focus on the significance of action research in teachers' professional development improvement of teaching and learning practices, opportunity to produce new knowledge, and engagement in research (Keegan, 2016). Action research is also considered as a change reform which influences teachers' self-reflection, professional development and learning outcomes (McLaughlin \& Ayubayeva, 2015). However, not many studies exist on the impact of action research on teachers' professional development within the Kazakhstani context. The studies, I found are written by McLaughlin, McLellan, Fordham, Chandler-Grevatt, and Daubney (2014) and McLaughlin and Ayubayeva (2015). The first literature provided information about the role of action research as a part of teachers' professional development in educational reforms. The latter discussed a brief history of action research advance from Great Britain to Nazarbayev Intellectual Schools in Kazakhstan, where the authors shared the different perspectives and experiences of the teachers involved in this project in relation to their emotions, knowledge and research. Action research in Kazakhstan was first introduced for teachers of Nazarbayev Intellectual Schools in 2012 (McLaughlin \& Ayubayeva, 2015).

Nazarbayev Intellectual Schools (NIS). The project "Network of 20 Intellectual schools" initiated by the First President of the Republic of Kazakhstan Nursultan Nazarbayev was launched in 2008 (McLaughlin \& Ayubayeva, 2015). Today all 20 NIS schools are operating in 14 different regions of Kazakhstan. The common mission of NIS is "to enhance the intellectual capacity of Kazakhstan through the development and implementation of an innovative, mathematics and scienceorientated, trilingual model of school system that integrates the best of Kazakhstani traditions, and that meets international standards of best practice" (AEO (Autonomous Educational Organisation) NIS 2020 development strategy, p. 5). According to McLaughlin and Ayubayeva (2015), the growth of the educational system is oriented towards the active involvement of teachers as change agents in the development of curriculum, assessment and pedagogical practices, which are new for Kazakhstani educational system. Thus, as the authors wrote, the decision to bring action research as a project to NIS was made to support teacher- practitioners in their new experience.

Almost four years have passed since teachers of NIS were first introduced to action research programme by the trainers from the SUPER (Schools-University Partnership for Educational Research) schools and the University of Cambridge cooperation (McLaughlin \& Ayubayeva, 2015). These trainers trained NIS teachers and supported them on action research within the periods of three years (McLaughlin \& Ayubayeva, 2015). The main purpose of this three year project was to support the development of teachers' professionalism in accordance with the NIS programme, and promote self-reflective and research culture of teaching and learning. Since the project implementation, several action research workshops have been provided for NIS head teachers, TRCs (Teacher Research Coordinators) and teachers (McLaughlin \& Ayubayeva, 2015).

Statement of the Problem. As three year support of trainers from Cambridge University and SUPER schools in implementing action research in Kazakhstan was accomplished in 2015, teachers of NIS are now conducting action research on their own with the gained action research knowledge and skills. For educators who initiated implementation of action research in Kazakhstan, it is important to observe the current situation in schools, compare the results with the previous studies within Kazakhstan and other countries, identify challenges and provide solutions. However, a lack of studies about action research implementation in Kazakhstan, its challenges and solutions do not give us full analysis of the current situation. It is important to explore action research implementation challenges in order to improve teachers' professional development. The lack of studies might be due to the short period of time passed since the first action research implementation in Kazakhstan. But, the existing studies within other countries (Jaipal \& Figg, 2011; Mingucci, 2001; Zhou, 2012), which are discussed in the Literature Review part of this thesis will contribute to address the research questions. Additionally, conducting this research, I, as a teacher research coordinator, intend to contribute to current existing literature about action research implementation issues in Kazakhstani teachers' practice.

Purpose of the Study. The purpose of this qualitative study is to explore the challenges of action research implementation and identify the ways of overcoming them as a part of teachers' professional development at one of the NIS schools in Kazakhstan.

Research Questions. The research questions, which guided the study, are:

1. What challenges are encountered that hinder, (if any) action research implementation in teachers' professional development at one of the NIS schools in Kazakhstan? 
2. What are the ways in which the practices of conducting action research can be improved?

Significance of the Study. Nowadays it is obvious that a lifelong learning process and the professional development of teachers are vital in the enhancement of the quality of education. Moreover, as McLaughlin and Ayubayeva (2015) stated, NIS teachers are involved in the process of educational policies' and programmes' development. It means that educational changes are mostly based on teachers' practices and professionalism. Action research as an effective method of analyzing practices is used in teachers' professional development. Exploration of action research implementation challenges is essential to increase the effectiveness of teacher research practice as a part of professional development in Kazakhstan. Identifying the action research implementation issues in teachers' research practices and providing the strategies for solving them, the study aims to contribute to improvement of teachers' research culture within Kazakhstani schools.

As mentioned above, many investigations about the importance of action research and its influence on professional development exist in the context of several different countries. However, the number of studies on action research implementation challenges in Kazakhstani educational system is limited. Therefore, the findings of this study will contribute to the effective implementation of action research in Kazakhstani schools and fill the gap in the research field.

The findings of the study are also beneficial for administrators and teachers of the Kazakhstani secondary schools, as well as, for other educational institutions. Teachers, as the main stakeholders of the project could understand the possible challenges of the action research implementation and improve their practice of conducting research. It can also help the school administrators to think of the effective methods and ways of overcoming the challenges teachers encounter during action research projects.

Findings and Discussion.

Role of Action Research in One of the NIS teachers' practice.

Teachers of the selected NIS started conducting action research in 2012. Five experienced participants of this study had the chance to participate in several action research workshops and seminars provided by SUPER and Cambridge University cooperation experts. According to the collected data all of the experienced participants claimed that action research is a powerful method used to improve their teaching practice. As one of the teachers shared, "Action research made huge positive changes in my practice. My traditional teaching style was teacher-centered, after conducting action research I changed it to student-centered" (Teacher 5). Study on NIS first action researchers' perception about the role of action research in their professional development by McLaughlin and Ayubayeva (2015) also presented positive attitudes of teachers who were involved in an action research project. This means that experienced teachers continue to believe and understand the effectiveness of action research in their practice. Referring to their first practice with action research, experienced participants stated that participation in different workshops and sharing ideas with colleagues helped them to improve knowledge and skills for conducting action research. They thought that action research contributed not only their, but also their colleagues' professional development. They also indicated the effectiveness of trainings provided by experts within the network, as well as, by TRCs within the school. Additionally, beginner action researchers also accepted action research as an impressive instrument that interests and encourages them. Nevertheless, experienced teachers (ET) claimed that they had passed plenty of issues to complete their action research, whereas beginner teachers (BT) stated that they needed to improve their knowledge and practice in order to successfully conduct action research projects.

\section{Challenges of Action Research Implementation in Kazakhstan}

Teachers are facing variety of academic and non-academic challenges when conducting action research. Analyzing some of the existing literature in the context of different countries, I can state several issues of action research implementation which are similar in various contexts - lack of theoretical knowledge about action research; lack of practice of conducting action research; lack of motivation; lack of resources; lack of support and time (Mingucci, 2001; Zeichner \& Klehr, 1999; Zhou, 2012). Moreover, I identified some other issues stated by Zeichner and Klehr (1999), which are logistical issues, which caused teachers' feeling of guilt; and shortage of collaboration between colleagues, which made teachers' frustrated and unmotivated. This emotional challenge, which is a typical issue occurred in teachers' practice when they intend to move from the "comfort" stage to "development" stage, is also discussed by McLaughlin and Ayubayeva (2015). Some of the discussed challenges of action research implementation in the Literature Review were relevant to this selected NIS teachers' practice. They are academic challenges and non-academic challenges, such as lack of resources and time. However, I identified several issues which were not discussed in literature, but 
they were mentioned by the participants and were unique to the selected NIS context. These issues were lack of teachers' English language knowledge to have access to research resources and interpret them. Also a few more challenges discussed in the Literature Review were not mentioned by participants, which are funding and logistics issues. The following Figure 1 demonstrates the challenges of action research implementation at this selected NIS.
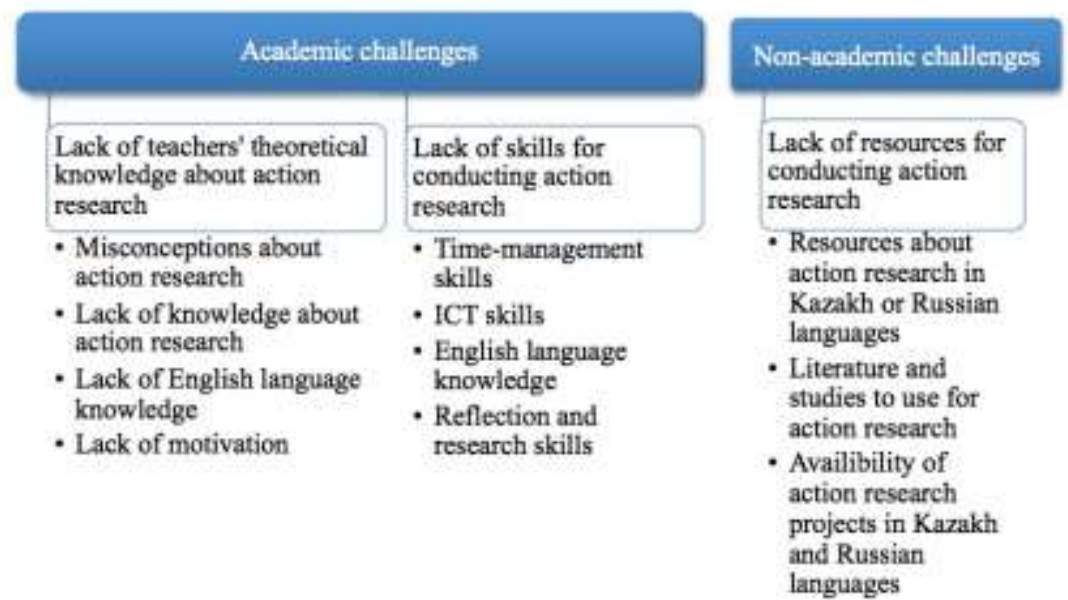

Fig.1. Challenges of action research implementation

Lack of teachers' theoretical knowledge about action research. One of the most frequent challenges researchers discussed was lack of theoretical knowledge of teachers who are going to undertake action research (Zeichner \& Klehr, 1999; Mingucci, 2001; Zhou, 2012). Findings show that this issue relates to teachers' misunderstanding the concept "action research", the role of action research; lack of motivation due to these misunderstandings, and shortage of English language knowledge to search and find more resources on action research itself and for their research. Teachers of this NIS encounter the same issues as do their colleagues around the world. They misunderstood the 'action research' and have many issues with research methodology which caused the decrease of their motivation to conduct action research.

Misconceptions about 'Action Research'. The findings of this study indicate that teachers had problems with perception of action research. According to Zhou (2012), school teachers recognised this method as an academic research undertaken in higher educational institutions.

Misconception of action research is spread among beginner action researchers rather than experienced ones. As quoted above, experienced teachers encountered the issue at the beginning of their practice with action research.

While interviewing teachers, I identified misconception of action research in a different way. In the view of some beginner teachers action research is "a teacher's individual research which develop classroom awareness" (Teacher 3, BT). Teacher 3 stated only one purpose of action research usage which is also related to shortage of action research knowledge, the challenge which is discussed in the next section of this chapter.

If we refer to teachers' past experience, we realize that Kazakhstani teachers were never involved in any kind of research. Their beliefs and values about education and teaching were different. So, a transformation from the old view, where they thought research is only for University academics, to a new view, where they have to be change agents confuses them. Therefore, I can say that the misconception of action research for this school teachers, who never were taught for research or had experience with research is a normal process at the beginning of action research implementation. However, teachers' misunderstanding in terms of effectiveness, implication and methods might be caused by their lack of knowledge about action research.

Lack of knowledge about action research. The majority of teachers at this NIS school lacked the knowledge about action research. Researchers agreed that lack of action research proficiency causes plenty of drawbacks in the way of implementing action research (Zeichner \& Klehr, 1999; Mingucci, 2001; Zhou, 2012). Beginner teachers declared that they did not have enough knowledge about action research in order to start conducting it earlier: "I wanted to conduct action research before, but I did not know how to start it. I also did not pay attention to action research, because I did not understand the importance of this research" (Teacher 5, BT). 
Experienced teachers who were coordinating action research projects at school also proved the existence of the challenges among the whole staff. From their point of view teachers' lack of knowledge of every step or aspect of action research process: (a) teachers do not know how to identify research questions and formulate the topic; (b) teachers' lack theoretical knowledge about research itself - use of research methods; (c) teachers have problems with planning of the research actions.

When all of the respondents were just starting the research they needed their experienced colleagues' continuous support, especially at topic formulation stage. "I did not know how to formulate the topic for my action research. But my colleagues helped me to solve this problem" (Teacher 4, BT). Moreover, experienced teachers mentioned that they still support their mentees or colleagues to identify and formulate the topic accurately. Additionally, from the experienced teachers point of view, this issue relates to shortage of teachers' knowledge and practice in doing action research. According to them, if practitioners acquire enough theoretical knowledge about action research methodology itself and practice the techniques systematically they would not have issues with topic formulation, data collection and analysis.

According to findings on lack of theoretical issues about action research, teachers face issues with methodology of action research. As I mentioned in a previous subsection, conducting research for teachers is new and challenging, even to understand the rationale. Therefore, as literature suggested they need time and effort to learn more about action research principles. However, as practitioners said they did not have access to database of knowledge about action research due to their lack of English language knowledge.

Lack of English language knowledge. The amount of worldwide research papers in Kazakh or Russian is much less than in English. Therefore, this NIS school science and non-English subject teachers $(60 \%)$ encounter the issue with the access to those resources in English. "Lack of English language is my own personal problem. I translate using Google translator. I spend a lot of time trying to understand the meaning of the sentence. Translation, of course, changes the meaning" (Teacher 2, BT).

As we can notice, one challenge causes other ones. Lack of English language knowledge causes other problems in terms of misinterpretation, lack of access to theory, loss of time and motivation. "My colleagues do not possess enough English language knowledge and skills which prevents them from using the worldwide database, such as EBSCO which is provided by our library for free. Because all the resources are in English" (Teacher 10, ET). Teachers have sufficient support and access to various type of resources via web databases or library. However, the challenge is in language which is inconvenient for most of the teachers.

Lack of motivation. Lack of theoretical knowledge and inaccuracy of planning lead teachers to loss of motivation to finalize their action research projects. As Zhou (2012) pointed out, unfamiliarity with action research methods and any complexities concerning research dissuade teachers from conducting action research. One of the beginner teachers (Teacher 3) emphasized that she lost motivation to do research due to the lack of knowledge.

According to McLaughlin and Ayubayeva (2015), emotions are important in action research. The transformation from the traditional style of teaching to a new style, where action research is an integral part of teachers' practice, makes teachers encounter several emotional issues. If teachers feel any anxiety, frustration or guilt, they lose their confidence and do not take risks to change their practices, hence causing a lack of motivation (Zhou, 2012).

Literature demonstrates that knowledge and skills are interrelated (Mingucci, 2001; Zhou, 2012). If teachers have knowledge they practice them and gain necessary skills. For example, if teachers have sufficient knowledge awareness about action research strategies then they might better implement them in practice. In addition, some fundamental skills such as reflection or language skills are demanding in learning to do research. Thus, a few basic skills identified as challenging for this NIS school teachers are discussed in the next subsection.

Lack of skills for conducting action research. Researchers agree that practitioners need basic skills to conduct action research (Mingucci, 2001; Zhou, 2012). According to them, the skills considered as significant for this project are reflective, research and time-management. However, there is another challenge which is exceptional for the selected NIS teachers, which is ICT skill. Therefore, the challenging skills for NIS action researchers are: lack of time-management skills, ICT skills, reflective and research skills. Each of the skills required for effective implementation of action research at this NIS is discussed in the following subsections.

Lack of resources for conducting action research. As mentioned in one of the previous subsections, one of the causes of the issue with resources is lack of English language skills of teachers. 
Teachers need English language knowledge when they search information about related to their research topic. Moreover, as findings demonstrated knowledge of English language is also preferable to study principles of action research and research methodology and to review existing research papers. Therefore, Mingucci's (2001) statement about lack of provision of resources for teachers is also relevant to this NIS school context. Teachers lack of resources about action research in Kazakh and Russian languages.

\section{Ways of Improving the Practice of Conducting Action Research.}

To address the second research question three main themes were figured out: (a) developing a positive collaborative environment; (b) provision of resources; (c) promotion of individual professional development. Each of the categories have subcategories, which are presented in Figure 2 below.
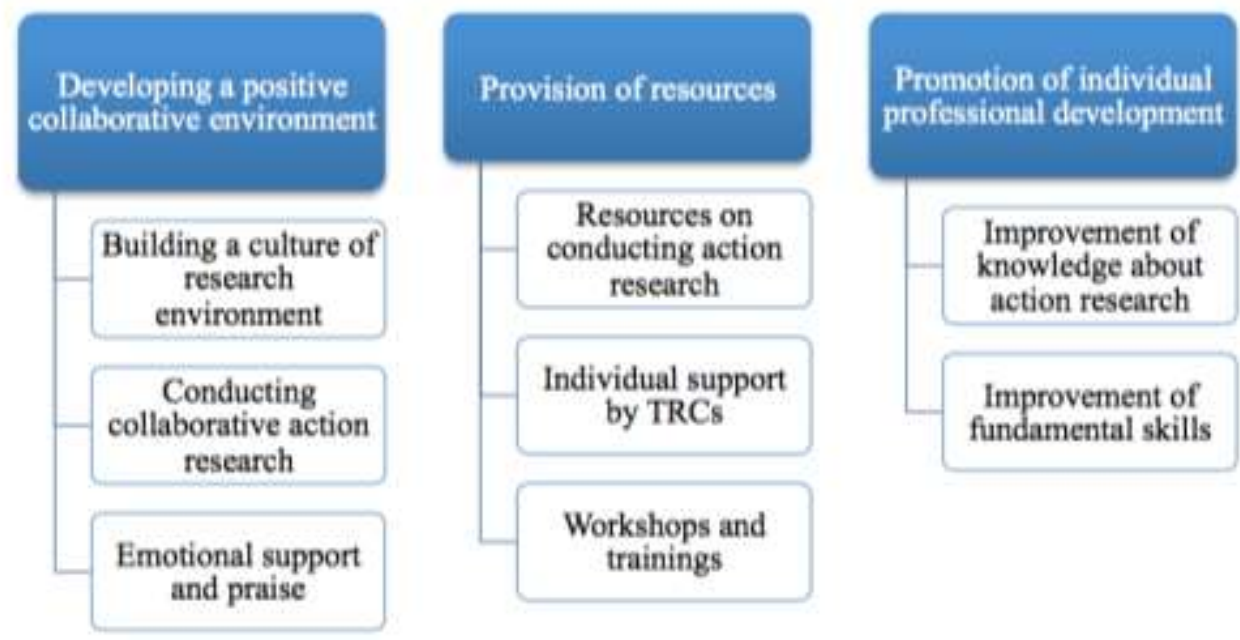

Fig.2. Ways of improving action research practice at one of the NIS

Developing a positive collaborative environment. Literature recommends building collaborative environment to improve the effectiveness of action research (Jaipal \& Figg, 2011). Half of the interviewees mentioned that collaboration is a key for effective professional development. According to the findings, collaboration in conducting action research is viewed in two ways: firstly, through creating culture of research within the school; and secondly, through undertaking collaborative action research projects within different departments.

Building a culture of research environment. One of the ways of developing collaboration in order to increase efficacy of teachers' action research is to build a culture of research within the school. The findings showed that one of the difficulties of implementing action research is lack of theoretical knowledge which causes the rest of the challenges - a decline in the level of interest, lack of skills necessary for research, and shortage of professional communication with colleagues. Therefore, experienced teachers suggested to improve the professional talks about action research in the school

Conducting collaborative action research. Three respondents thought that collaboration between colleagues is increased if teachers undertake not only individual projects, but also collaborative action research. Some of the teachers who work in collaboration with other colleagues shared:

"Now I am working with Russian and ICT teacher on one action research. Working in collaboration is effective; Russian teacher is very experienced action researcher, If I do not understand some methods or have questions on some aspects of action research, we can easily discuss and solve the issue. Our topic is connected with ICT usage in the classroom, so the help and support of ICT teacher is huge. I can state, we are working productively" (Teacher 1, BT).

Emotional support and praise. As teachers encounter emotional issues during their action research practice, it is obvious that they need emotional support from the school administration team, colleagues and TRCs. Also as McLaughlin and Ayubayeva (2015) indicated, teachers face a lot of emotional discomforts when they attempt to change their regular practice and try to experiment. So they suggested teachers should be emotionally prepared for having a lot of challenges, such as frustration, feeling of guilt, and anxiety. So as literature demonstrates teachers' lack of confidence, feeling of guilt due to lack of necessary skills are normal and require from the school leadership team support and praise. Literature suggests to provide several types of support (Caro-Bruce \& McCreadie, 1994). The findings also indicated that teachers need support from several sources. They ask support from school administration in providing resources, time to 
conduct action research, and help with the publication of their research findings; and from experienced action researchers and TRCs support in terms of continuous individual meetings and training on research methodologies. Also support from other colleagues in terms of English language, ICT practice and work with databases might be effective for action researchers.

Provision of resources. Teachers indicated that lack of resources hinders the effective action research implementation. According to Zhou (2012), teachers lack access to online resources and databases. However, findings demonstrate full access of this NIS teachers to online database, such as EBSCO. However, participants argued that they lack of sufficient resources in Kazakh or Russian languages. Participants cited several ways of addressing this issue.

Resources about conducting action research. According to findings, teachers, firstly, need sufficient resources on action research itself; and secondly, they ask for resources in Kazakh or Russian relevant to their research. "To solve this issue there should be special teachers' handbooks or guidelines on how to conduct action research which can help me with examples of analysis of quantitative or qualitative data" (Teacher 9, ET).

Experienced teachers are a main source of resource for beginners. As we discussed before experienced teachers can provide support in terms of not only counseling, but also preparing handbooks, guidance, or even collection of action research samples. However, school administration's support and praise for experienced action researchers are also essential.

Individual support by TRCs. According to teachers' responses, individual support provided by teacher research coordinators is beneficial. All of the respondents indicated that mostly they had learned from their experienced colleagues who worked as a TRC. Therefore, provision of resources in a way of giving support for experienced teachers to coordinate implementation of action research and work individually with smaller group of people. As participants mentioned, TRCs at school must support them in a variety of ways. "We need professional teacher research coordinators. (We have them in our school.) However, their number should be greater to cover a majority of teachers" (Teacher 6, ET).

Moreover, beginner teachers believe that if they had more individual support by TRCs, they could be more productive would be the work. "We need continuous support from teacher research coordinators. I like research. However, I need individual support" (Teacher 4, BT).

Workshops and trainings. More than half of the respondents $(60 \%)$ found out the effectiveness of professional development workshops and trainings. According to them, professional trainings provided by specialists had huge impact on their professional development and involvement in action research. "After attending the workshop I started to conduct action research. Workshops are useful and motivated me" (Teacher 7, ET).

Moreover, as one of the experienced teachers explained, workshops and training develop teachers not only awareness about action research, but also the skills which are necessary for conducting action research: "They need practical trainings on ways of allocating resources, ways of getting information, and sharing experience" (Teacher 10, ET).

Promotion of individual professional development. Teachers of this school have all opportunity to conduct action research. However, the findings show that teachers use them too little to possess necessary knowledge and skills. According to literature, teachers should professionally develop themselves to succeed in a professional world. This is also true for action research. Analyzing the recommendations teachers shared, I propose three aspects of professional development which can be enjoyed by teachers and supported by school TRCs and administrators: (1) improvement of awareness about action research; (2) improvement of fundamental skills required for conducting action research; and (3) improvement of teachers self-attitude towards action research.

Conclusions. Findings of the study demonstrated that teachers of This NIS school encounter several academic and non-academic challenges when they conduct action research. Experienced teachers shared the challenges they faced at the beginning of their practice, while beginners indicated the challenges they were facing in current days. Most of the challenges they pointed out are related to the literature. They are academic challenges, such as: lack of theoretical knowledge about action research, lack of sufficient skills to conduct action research and non-academic challenges, such as lack of support in terms of providing trainings about action research, and emotional issues. However, several other identified issues are unique to the This NIS school context. These issues are: lack of teachers' English language knowledge, lack of resources in Kazakh and Russian languages about action research, and lack of teachers' ICT skills to edit, format and publish their projects. Moreover, a few more issues presented in Findings and Discussions chapters, such as: lack of motivation and lack of time- management skills, lack of reflective 
and research skills; all are caused by the key issues of action research implementation which are lack of knowledge and practice of conducting action research.

Findings do not provide sufficient data on difference challenges in experienced and beginner teachers' practice. Experienced action researchers gave information from their first experience when they started action research. Therefore, the issues are mostly relevant for novice action researchers. The most important contribution of experienced teachers was in terms of provision of recommendations to overcome the issues.

Findings also presented recommendations for improving the identified action research implementation challenges. As I stated, the key issues of action research implementation are lack of knowledge and practice of conducting action research; most of the teachers need continuous support from several sources - school administration, TRCs and experienced colleagues. According to them, the most efficient solution is creating a collaborative environment and building a culture of action research within the school. In order to successfully implement action research and build research culture, teachers need support from their colleagues and school administration with provision of resources in terms of workshops, training, materials in Kazakh and Russian languages about action research, emotional support and praise. However, some of them argue that they have to be self-organized and improve their self- learning. The Findings demonstrate that teachers need to network and participate in many action research forums, meetings and training provided by the NIS network and school TRCs. Thus, the major recommendation for teachers is to stay open, positive and motivated to be lifelong learners.

\section{REFERENCES}

1. Alshenqeeti, H. (2014). Interviewing as a data collection method: A critical review, English Linguistics Research, 3(1), 39-45. doi:10.5430/elr.v3n1p39

2. Bargal, D. (2006). Personal and intellectual influences leading to Lewin's paradigm of action research Towards the 60th anniversary of Lewin's 'Action research and minority problems' (1946). Action Research, 4(4). Retrieved from http://arj.sagepub.com/content/4/4/367

3. Campbell, C., Tovar, D. (2006). Action research as a professional development tool for teachers and administrators, Applied Language Learning, 16(1), 75-80. Retrieved from http://www.dliflc.edu/academicjournals-applied-language-learning/

4. Creswell, J. W. (2014). Educational research: Planning, conducting and evaluating quantitative and qualitative research. Boston, MA: Pearson.

5. Elliott, J. (2015). Educational action research as the quest for virtue in teaching, Educational Action Research, 23(1), 4-21. doi: 10.1080/09650792.2014.994017

6. Handbook for the $1^{\text {st }}$ level teacher, 2015. Center of Excellence, Kazakhstan.

7. Hardy, W., Rodman, J. (2016). Action research: A systematic approach to the social component of the dimension, Military Review, 96(1), 88.

8. Hildrum, J., Strand, G. (2007). Overcoming challenges in writing about action research - the promise of the development story, Syst Pract Act Res, 20, 77-89. doi:10.1007/s11213-006-9051-3

9. Jaipal, K., Figg, C. (2011). Collaborative action research approaches promoting professional development for elementary school teachers, Educational Action Research, 19(1), 59-72.

10. Lewin, K. (1946). Action research and minority problems. Journal of Social Issues, 2(4), 34-46.

11. Malinen, O., Vaisanen, P., \& Savolainen, H. (2012). Teacher education in Finland: A review of a national effort for preparing teachers for the future, The Curriculum Journal, 23(4), 567-584. doi:10.1080/09585176.2012.731011

12. McGee, A. (2008). Critical reflections of action research used for professional development in a Middle Eastern Gulf State, Educational Action Research, 16(2), 235-250. doi:10.1080/09650790802011882

13. McLaughlin, C., Ayubayeva, N. (2015). 'It is the research of self experience': Feeling the value in action research, Educational Action Research, 23(1), 51-67. doi:10.1080/09650792.2014.994018

14. Mingucci, M. (2001). Action research as ESL teacher professional development. Retrieved from ProQuest Dissertations and Theses.

15. Mpokosa, C., Ndaruhutse, S., McBride, S., Nock, S., \& Penson, J.(2008). Managing Teachers: The Centrality of teacher management to quality education. Lessons from Developing Countries. VSO: CFBT Education Trust.

16. Ozturk, M. (2013). The value teachers add to educational systems: The case of Finland, Hacettepe University Journal of Education, 1, 298-310.

17. Smith, K., Sela, O. (2005). Action research as a bridge between pre-service teacher education and inservice professional development for students and teacher educators, European Journal of Teacher Education, 28(3), 293-310.

18. Zeichner, K., Klehr, M. (1999). Teacher research as professional development for p-12 educators. Retrieved from http:/www.ericsp.org/digests/TeacherResearch.htm

19. Zhou, J. (2012). Problems teachers face when doing action research and finding possible solutions, Chinese Education and Society, 45(4), 68-80. 